Tropical Journal of Pharmaceutical Research May 2017; 16 (5): 1113-1119

ISSN: $1596-5996$ (print); 1596-9827 (electronic)

(C) Pharmacotherapy Group, Faculty of Pharmacy, University of Benin, Benin City, 300001 Nigeria.

All rights reserved.

Available online at http://www.tjpr.org

Original Research Article

http://dx.doi.org/10.4314/tjpr.v16i5.20

\title{
Effect of steam explosion pre-treatment on molecular structure of sweet potato starch
}

\author{
Guanglei Li ${ }^{\star}$, Mengxue Chen, Fei Li, Jie Zeng and Junliang Sun \\ School of Food Science, Henan Institute of Science and Technology, Xinxiang, 453003, China
}

${ }^{*}$ For correspondence: Email: Igl70_hist@163.com; Tel: +86 3733693693

Sent for review: 12 December 2016

Revised accepted: 23 April 2017

\begin{abstract}
Purpose: To examine the effect of steam-explosion (SE) strength on the molecular structure of sweet potato starch.

Methods: Sweet potato starch was pre-treated using SE method. The effects of SE pressure and pressure-holding time on the molecular structure of the sweet potato starch were investigated by gel chromatography (GPC), infrared spectroscopy, and grading analysis.

Results: The molecular weight (MW) of the starch pre-treated by SE technology decreased with increasing explosion pressure and pressure-holding time; however, the individual MW of amylopectin and amylose declined from 439,834 and 6578 to 238,603 and 4845, respectively. Furthermore, the peak area ratio (obtained by GPC) of amylopectin decreased from 84.39 to $65.16 \%$ while that of amylose increased from 15.61 to $34.84 \%$. No new absorption peaks were found in the infrared spectra of sweet potato starch following SE pre-treatment. Crystallization index and median diameter of sweet potato starch increased from 1.661 to 1.959 and from $13.73 \mu \mathrm{m}$ to $76.36 \mu \mathrm{m}$, respectively, with rising pressure and pressure-holding time, following SE pre-treatment.

Conclusion: SE pre-treatment effectively degrades the degree of polymerisation of molecular chains in sweet potato starch and enhances the degree of crystallinity thereof. SE method is an approach for the production of sweet potato starch with high-level anti-digestion characteristics.
\end{abstract}

Keywords: Sweet potato starch, Steam-explosion, Molecular weight, Degree of crystallinity, Particle diameter

Tropical Journal of Pharmaceutical Research is indexed by Science Citation Index (SciSearch), Scopus, International Pharmaceutical Abstract, Chemical Abstracts, Embase, Index Copernicus, EBSCO, African Index Medicus, JournalSeek, Journal Citation Reports/Science Edition, Directory of Open Access Journals (DOAJ), African Journal Online, Bioline International, Open-J-Gate and Pharmacy Abstracts

\section{INTRODUCTION}

Steam-explosion (SE) treatment, developed by $\mathrm{WH}$ Mason in 1928, is a method used for pretreating biomasses by heating raw materials to between 0.69 and $4.83 \mathrm{MPa}$ for several seconds (or even minutes) using saturated steam at 160 to $260{ }^{\circ} \mathrm{C}$ and then reducing the pressure suddenly to atmospheric pressure [1]. The primary working principle of SE is to expose raw materials to steam under high temperature and pressure for a specific period of time where the materials swell owing to the presence of the overheated liquid and then their pores are filled with steam. When the high pressure is rapidly released to the surrounding environment (within $0.00875 \mathrm{~s}$ ), the water vapour inside the materials expands and exerts pressure on the cell walls, which causes the materials to undergo explosive decompression [2-4].

Although it has been 80 years since the technology was first proposed, SE treatment is used for treating wood fibres to separate components and change the structure of fibrous materials, so as to improve the accessibility of 
celluloses to enzymes and chemical reagents [57]. However, there are no relevant reports about the application of SE treatment in the pretreatment of sweet potato starch. SE has been increasingly considered as one of the most efficient, environmentally friendly, and costeffective pre-treatment methods for transforming biomass resources and can be carried out on a large scale [8].

In the present work, sweet potato starch was pretreated by using SE technology, so as to increase the starch crystallinity and enhance its surface textural roughness. The aim of the research is to provide theoretical support for the application of SE technology in the pre-treatment of sweet potato starch, as this may further promote its application in the food and pharmaceutical industries.

\section{EXPERIMENTAL}

\section{Materials}

Sweet potato starch was purchased from Agriculture Development Limited Company, Hezai, Henan. a-amylase and glucoamylase were kindly provided by Fuyuan Biological Science and Technology Limited Company, Zhengzhou, Henan. The other chemicals were of analytical grade.

\section{SE treatment}

Sweet potato starches $(200 \mathrm{~g})$ were added to a cylinder (QBS-80-type testbed for steamexplosion produced by Zhengdao Heavy Machinery Factory in Hebi, Henan Province, China). SE treatment was performed at 1.2-2.4 $\mathrm{MPa}$ for $20-80 \mathrm{~s}$. Finally, the materials extruded from the cylindrical intracavity were collected and dried [7].

\section{Preparation of sample solution of starch}

Samples of sweet potato starches (mass, $50 \mathrm{mg}$ ) were weighed and dissolved in a $10 \mathrm{~mL}$ dimethyl sulfoxide solution with a concentration of $90 \%$. Then the solution was stirred at $60^{\circ} \mathrm{C}$ for $1 \mathrm{~h}$ by using a magnetic heating stirrer so as to obtain a clarified standard solution.

Subsequently, the standard solution was centrifuged for $20 \mathrm{~min}$ at a rate of rotation of $3000 \mathrm{rpm}$. After being filtered through a nylonmicroporous membrane (0.45 $\mu \mathrm{m}$ mesh), the supernatant was studied by gel permeation chromatography (GPC) with an injection amount of $100 \mu \mathrm{L}$ [9].

\section{GPC analysis}

The chromatographic column used in the GPC was of the ultra-hydrogel linear type. The mobile phase used in the GPC was $0.1 \mathrm{~mol} / \mathrm{L}$ sodium nitrate filtered by a micro-filtration membrane of $0.22 \mu \mathrm{m}$ aperture flowing at a velocity of 0.6 $\mathrm{mL} / \mathrm{min}$. The column temperature was $45^{\circ} \mathrm{C}$.

\section{Fourier transform infrared spectroscopy (FT- IR)}

FT-IR (Nicolet 470; Perkin Elmer Inc., Waltham, MA, USA) was adopted to determine the structure of the sweet potato starch according to the method reported by Li et al [10].

\section{Determination of size distribution of starch granules}

A certain amount of the starch samples was weighed and added to the cuvette of a laser particle size analyser. Then the starch granules were uniformly dispersed through ultrasonic oscillation using distilled water as the dispersing agent. When the shading rate reached to $15 \%$ to $18 \%$, the range and distribution of particle sizes were determined three times and the mean average values were calculated. The refractive index of the starch granules was 1.53 while that of the dispersing agent was 1.33 .

\section{Statistical analysis}

Statistical analysis was carried out using DPS 7.05 software (Zhejiang University, Hangzhou, China). All measurements were repeated three times and mean \pm standard deviation obtained. Statistical comparisons were carried out using Dixon test, with $p<0.05$ considered statistically significant.

\section{RESULTS}

\section{Effects of SE pre-treatment on the MW of sweet potato starch}

The high-performance gel chromatogram of the pre-treated sweet potato starch samples is shown in Figure 1. It can be seen from Figure 1 that amylose and amylopectin constitute the major components of natural sweet potato starch. As molecules with larger MW were eluted first during gel chromatography, so amylopectin was eluted earlier than amylose.

The sweet potato starch were pre-treated by use of the proposed SE technology to study the effects of explosion pressure and pressureholding time on the MW distribution of the sweet 
potato starch, the gel chromatograms are shown in Figure 2 and Figure 3.

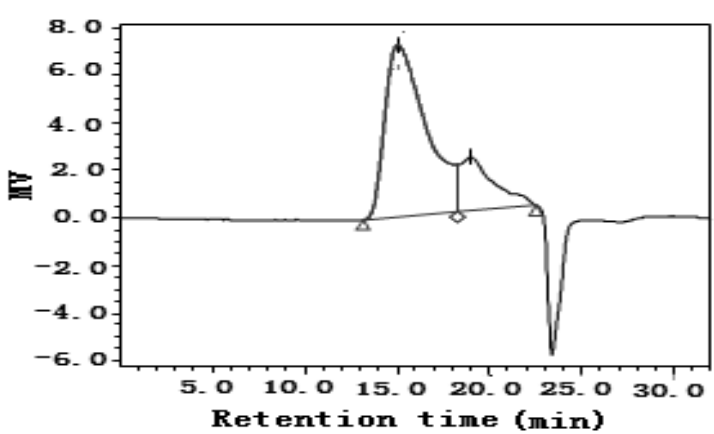

Figure 1: Gel chromatogram of sweet potato starch

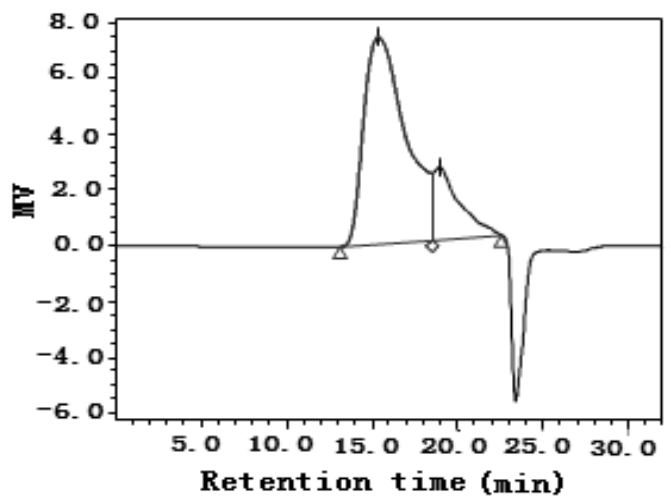

(a) 1.2 Mpa,40 s
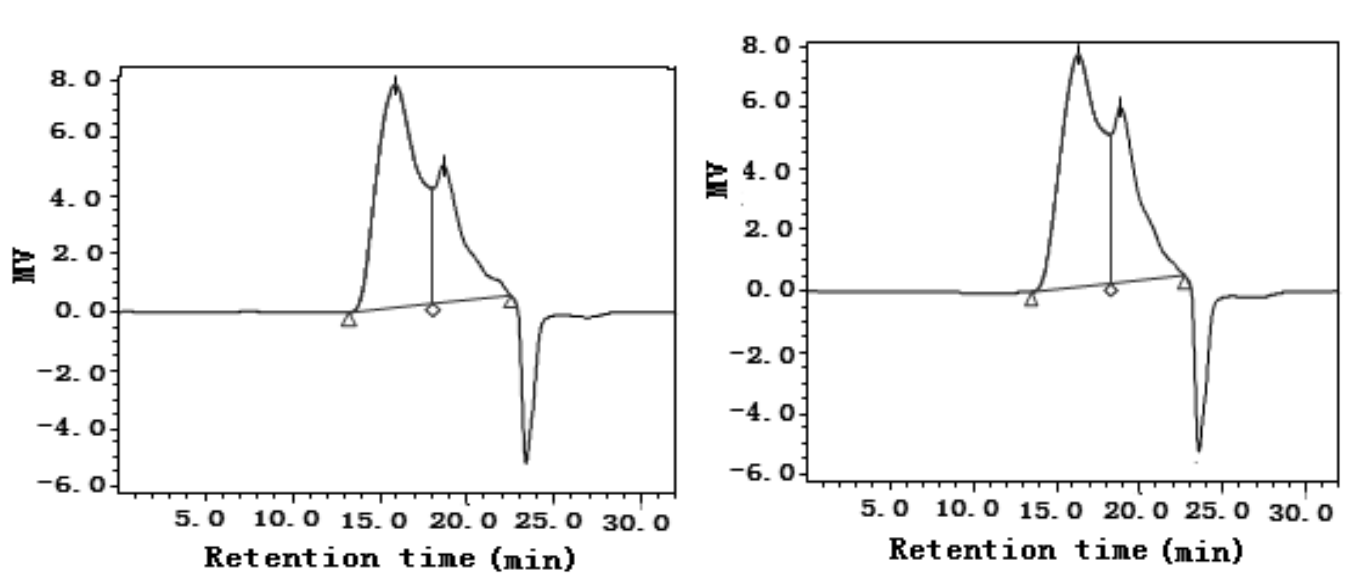

(c) $2.0 \mathrm{Mpa}, 40 \mathrm{~s}$

(d) $2.4 \mathrm{Mpa}, 40 \mathrm{~s}$

Figure 2: Effect of steam exploded pressure on gel chromatogram of sweet potato starch

Table 1: Effect of steam exploded pressure on molecular weight distribution of sweet potato starch

\begin{tabular}{lcccc}
\hline \multirow{2}{*}{$\begin{array}{l}\text { SE pressure } \\
\text { (MPa) }\end{array}$} & \multicolumn{2}{c}{ Peak 1 } & \multicolumn{2}{c}{ Peak 2 } \\
\cline { 2 - 5 } & $\mathbf{M}_{\mathbf{W}}$ & Peak area ratio (\%) & $\mathbf{M}_{\mathbf{W}}$ & Peak area ratio (\%) \\
\hline 0 & 439834 & 84.39 & 6578 & 15.61 \\
1.2 & 389287 & 79.02 & 5654 & 20.98 \\
1.6 & 320346 & 76.72 & 5354 & 23.84 \\
2.0 & 284631 & 69.63 & 5126 & 30.37 \\
2.4 & 238603 & 65.16 & 4845 & 34.84 \\
\hline
\end{tabular}

Key: Pressure-holding time was $40 \mathrm{~s}$, and moisture content of samples was $12.37 \%$.
Table 1 and Table 2 show that after the sweet potato starches had been pre-treated, the MWs of both amylopectin and amylose decreased to me extent. With the increase of the explosion pressure and the rise time of the treatment, the area of the amylopectin (with its longer molecular chains) peaks gradually declined while that of yith its shorter molecular chains) peaks increased. The reason for this was probably that under the effect of the SE treatment. In addition, litting decomposition also occurred on the $\alpha-1$, 4 glucosidic bonds so as to produce more micromolecular starches, resulting in decreasing MWs

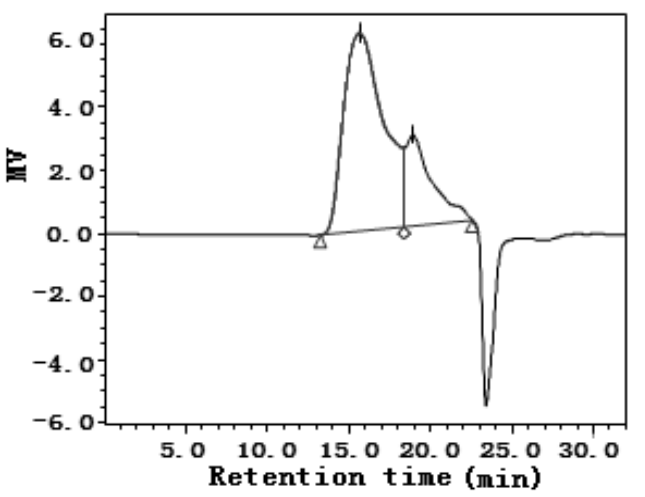

(b) $1.6 \mathrm{Mpa}, 40 \mathrm{~s}$ 


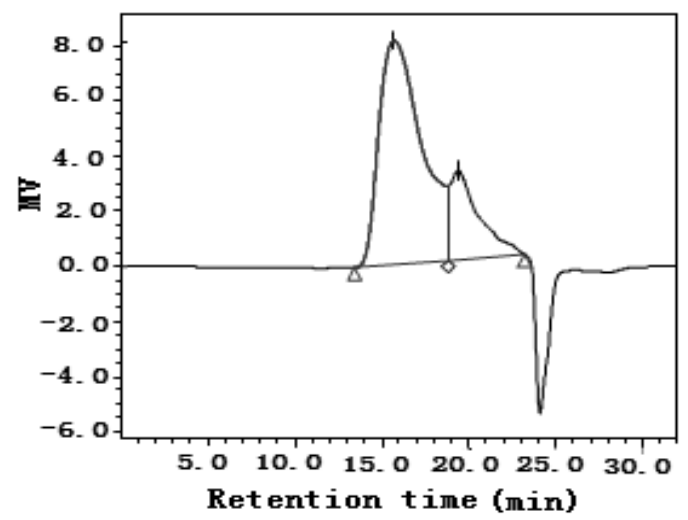

(a) $1.2 \mathrm{Mpa}, 20 \mathrm{~s}$

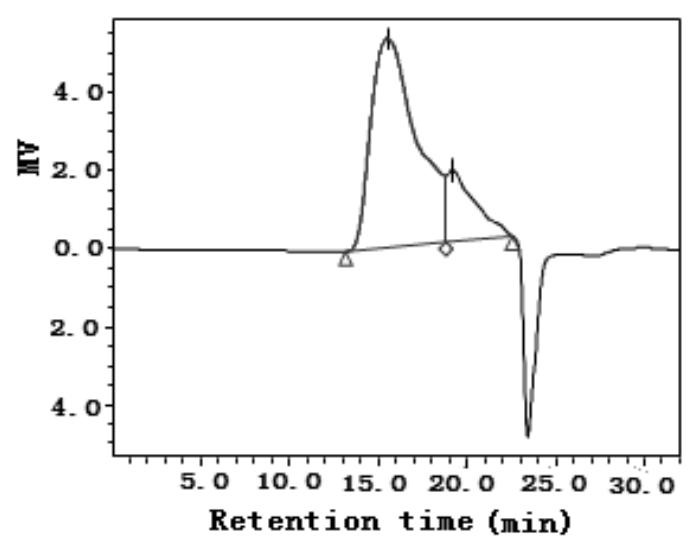

(c) $1.2 \mathrm{Mpa}, 60 \mathrm{~s}$

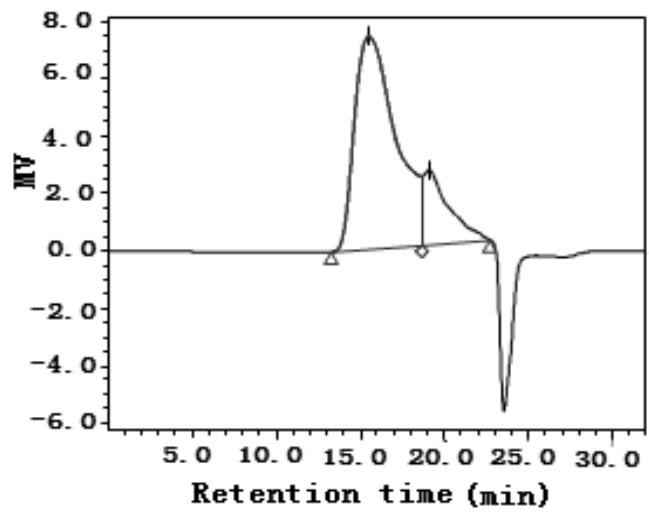

(b) $1.2 \mathrm{Mpa}, 40 \mathrm{~s}$

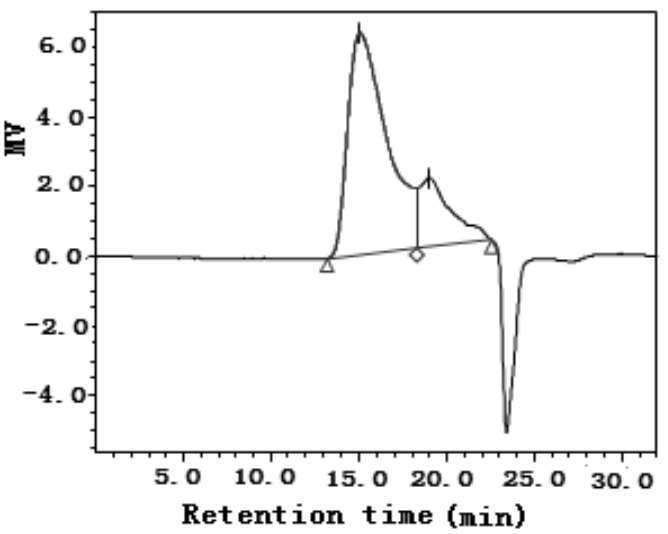

(d) $1.2 \mathrm{Mpa}, 80 \mathrm{~s}$

Figure 3: Effect of SE pressure-holding time on gel chromatogram of sweet potato starch

Table 2: Effect of SE pressure-holding time on molecular weight distribution of sweet potato starch

\begin{tabular}{lcccc}
\hline \multirow{2}{*}{ Holding time (s) } & \multicolumn{3}{c}{ Peak 1 } & \multicolumn{2}{c}{ Peak 2 } \\
\cline { 2 - 5 } & $\mathbf{M}_{\mathbf{W}}$ & Peak area ratio (\%) & $\mathbf{M}_{\mathbf{W}}$ & Peak area ratio (\%) \\
\hline 0 & 439834 & 84.39 & 6578 & 15.61 \\
20 & 419769 & 80.90 & 5793 & 19.10 \\
40 & 389287 & 79.02 & 5654 & 20.98 \\
60 & 355499 & 74.48 & 4526 & 25.52 \\
80 & 332806 & 67.57 & 3716 & 32.43 \\
\hline
\end{tabular}

Key: SE pressure was $1.2 \mathrm{Mpa}$, and moisture content of samples was $12.37 \%$

of the starches. Amylopectin was degraded and a-1, 6 glucosidic bonds were spilt to form new shorter amylose molecules through using the proposed SE treatment. Additionally, $\alpha-1,4$ glucosidic bonds in the longer amylose chain were damaged, changing longer amylose molecules to shorter one. As a result, the peak area ratio of the short-chain peaks increased.

\section{Effect of SE pre-treatment on the infrared spectrum of sweet potato starch}

The infrared spectra of the sweet potato starches pre-treated by SE technology are shown in Figure 4 and Figure 5.

Figures 4 and 5 show that no new absorption peaks occurred on the infrared spectrogram of the pre-treated sweet potato starches by comparing them with that of the original starch samples. That is to say, no new functional groups appeared on the molecular skeleton of the sweet potato starch, which suggested that the chemical structure of the sweet potato starch was unchanged after SE treatment.

The infrared spectrum of the starch samples was easily affected by the changes in starch crystallisation, the conformation of molecular chains, and the presence of helical structures. Starch is a poly-crystalline high-molecular weight polymer and its infrared spectrogram shows a specific absorption band sensitive to crystallization when it is crystalline. Moreover, the strength of the crystalline region is related to the degree of crystallinity: the higher the degree 


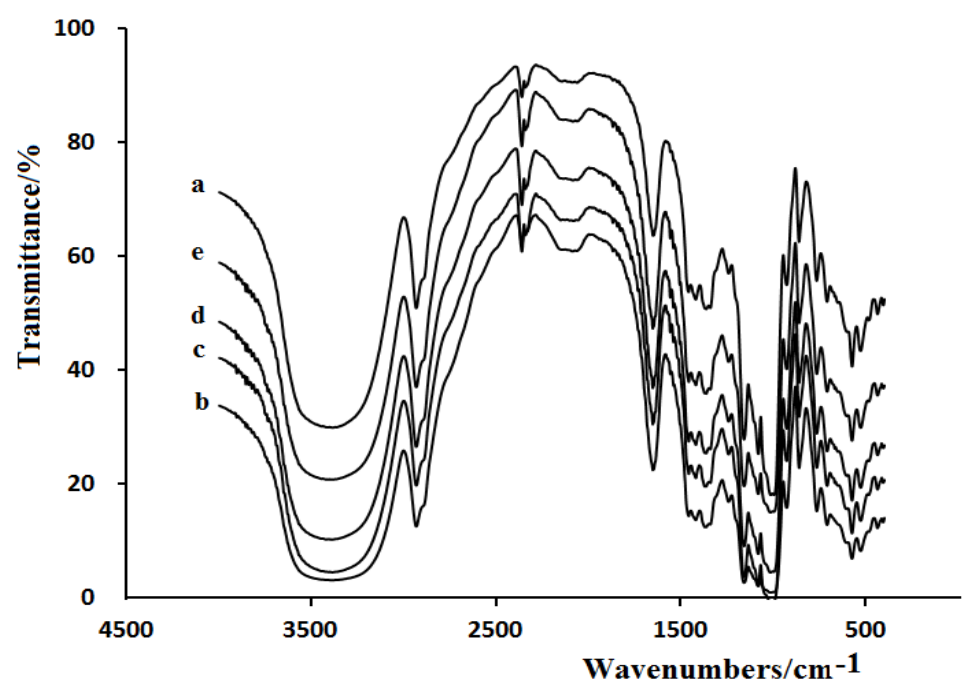

Figure 4: Effects of steam exploded pressure on infrared spectrum of sweet potato starch. Key: $a=0 \mathrm{Mpa}, 0 \mathrm{~s}$; $b=1.2 \mathrm{Mpa}, 40 \mathrm{~s} ; c=1.6 \mathrm{Mpa}, 40 \mathrm{~s} ; d=2.0 \mathrm{Mpa}, 40 \mathrm{~s} ; e=2.4 \mathrm{Mpa}, 40 \mathrm{~s}$

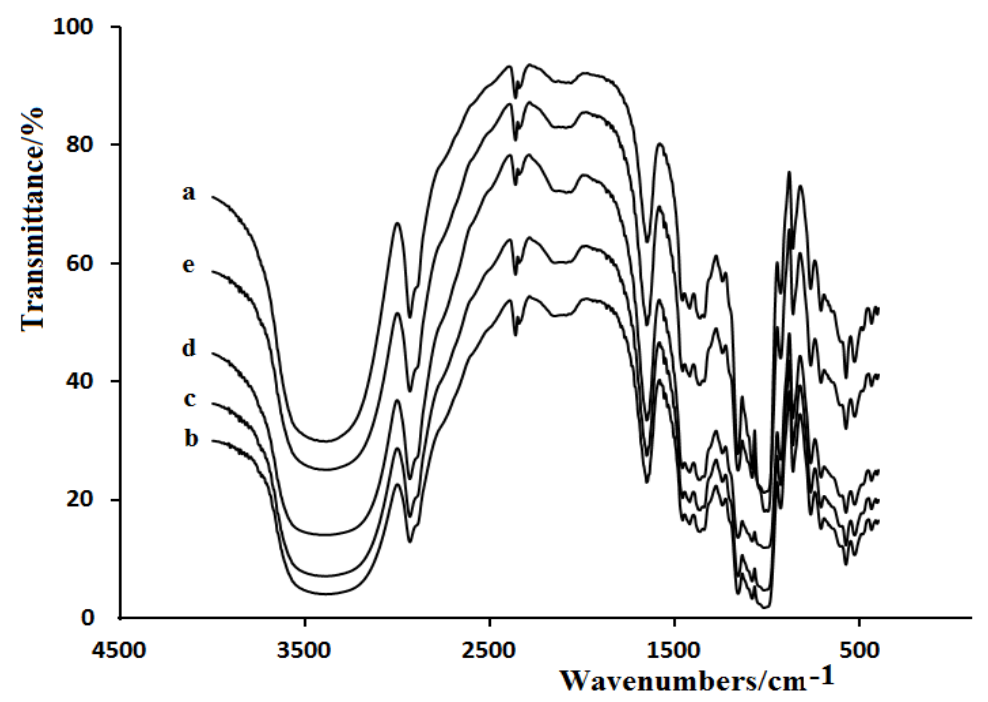

Figure 5: Effect of SE pressure-holding time on infrared spectrum of sweet potato starch. Key: $a=0 \mathrm{Mpa}, 0 \mathrm{~S}$; $b=1.2 \mathrm{Mpa}, 20 \mathrm{~s} ; \mathrm{c}=1.2 \mathrm{Mpa}, 40 \mathrm{~s} ; d=1.2 \mathrm{Mpa}, 60 \mathrm{~S} ; \mathrm{e}=1.2 \mathrm{Mpa}, 80 \mathrm{~s}$

of crystallinity, the stronger the strength of the crystalline region, otherwise, that of amorphous regions increased [11]. The infrared crystallization index of the starches was computed using Eq. 1.

$$
N-O^{\prime} K I=\frac{\log \left(\frac{1}{T 1158}\right)}{\log \left(\frac{1}{T 2931}\right)}
$$

where $\mathrm{N}-\mathrm{O}^{\prime} \mathrm{KI}$ represents the infrared crystallization index, $\mathrm{T} 1158$ refers to the transmittance of $\mathrm{C}-\mathrm{O}-\mathrm{C}$ stretching vibration absorption peak at $1,158 \mathrm{~cm}^{-1}$, and T2931 refers to the transmittance of the $\mathrm{C}-\mathrm{CH}_{2}-\mathrm{C}$ stretching vibration absorption peak at $2,931 \mathrm{~cm}^{-1}$. Changes in the degree of crystallinity of starches can be represented by analysis of the two stretching vibrations.

Changes in the crystallization indices of the sweet potato starch samples pre-treated by the SE technology are shown in Table 3 and Table 4.

It can be seen from Table 3 that the crystallisation indices of the sweet potato starch samples increased from 1.661 to 1.959 (at 2.4 $\mathrm{MPa}$ ) with rising explosion pressure. Table 4 shows that the crystallisation index increased from 1.661 to 1.917 (at $80 \mathrm{~s}$ ) with increasing pressure-holding time. The aforementioned results indicated that, longer molecular chains in the molecules of the sweet potato starch samples were broken to form shorter pieces, which were liable to form molecular crystalline textures in the starch samples. As a result, the 
structural characteristics of the crystallising layers of the starches were gradually strengthened, while that of their amorphous layers decreased.

Table 3: Effect of steam exploded pressure on infrared crystallisation index of sweet potato starch

\begin{tabular}{|c|c|c|c|}
\hline $\begin{array}{l}\text { SE } \\
\text { pressure } \\
\text { (MPa) }\end{array}$ & $\mathrm{T}_{\lambda 1158}(\%)$ & $\mathrm{T}_{\lambda 2931}(\%)$ & $\mathrm{N}-\mathrm{O}^{\prime} \mathrm{KI}$ \\
\hline 0 & 34.396 & 52.612 & 1.661 \\
\hline 1.2 & 16.814 & 36.225 & 1.756 \\
\hline 1.6 & 17.065 & 36.986 & 1.778 \\
\hline 2.0 & 18.494 & 39.349 & 1.809 \\
\hline 2.4 & 24.604 & 48.905 & 1.959 \\
\hline
\end{tabular}

Table 4: Effects of SE pressure-holding time on infrared crystallisation index of sweet potato starch

\begin{tabular}{|c|c|c|c|}
\hline $\begin{array}{l}\text { Holding } \\
\text { time (s) }\end{array}$ & $\mathbf{T}_{\lambda 1158}(\%)$ & $\begin{array}{c}T_{\Lambda 2931}( \\
\%)\end{array}$ & $\mathrm{N}-\mathrm{O}^{\prime} \mathrm{KI}$ \\
\hline 0 & 34.396 & 52.612 & 1.661 \\
\hline 20 & 16.547 & 35.245 & 1.725 \\
\hline 40 & 16.807 & 36.251 & 1.757 \\
\hline 60 & 21.819 & 43.374 & 1.823 \\
\hline 80 & 23.786 & 47.282 & 1.917 \\
\hline
\end{tabular}

Effect of SE pre-treatment on the particle diameter

Changes in the particle diameters of the sweet potato starches pre-treated with the proposed SE technology were displayed in Table 5 and Table 6.

Table 5: Effect of steam exploded pressure on particle diameters of sweet potato starch

\begin{tabular}{lcc}
\hline $\begin{array}{l}\text { SE } \\
\text { pressure } \\
(\mathrm{MPa})\end{array}$ & $\begin{array}{c}\text { Median diameter } \\
(\boldsymbol{\mu \mathrm { m } )})\end{array}$ & $\begin{array}{c}\text { Volume } \\
\text { mean } \\
\text { diameter } \\
(\boldsymbol{\mu m})\end{array}$ \\
\hline 0 & $13.73 \pm 0.02$ & $14.68 \pm 0.02$ \\
1.2 & $32.85 \pm 0.02$ & $38.85 \pm 0.02$ \\
1.6 & $47.85 \pm 0.03$ & $59.85 \pm 0.03$ \\
2.0 & $60.89 \pm 0.01$ & $74.28 \pm 0.01$ \\
2.4 & $68.81 \pm 0.02$ & $85.80 \pm 0.02$ \\
\hline
\end{tabular}

Table 6: Effect of SE pressure-holding time on particle diameters of sweet potato starch

\begin{tabular}{lcc}
\hline $\begin{array}{l}\text { Holding time } \\
(\mathbf{s})\end{array}$ & $\begin{array}{c}\text { Median } \\
\text { diameter } \\
(\boldsymbol{\mu m})\end{array}$ & $\begin{array}{c}\text { Volume mean } \\
\text { diameter }(\boldsymbol{\mu m})\end{array}$ \\
\hline 0 & $13.73 \pm 0.02$ & $14.68 \pm 0.02$ \\
20 & $21.85 \pm 0.02$ & $23.85 \pm 0.02$ \\
40 & $32.85 \pm 0.02$ & $38.85 \pm 0.02$ \\
60 & $57.89 \pm 0.01$ & $66.28 \pm 0.01$ \\
80 & $76.36 \pm 0.02$ & $93.53 \pm 0.02$ \\
\hline
\end{tabular}

It can be seen from Table 5 and Table 6 that the particle granularity of the pre-treated sweet potato starch significantly increased. For example, the median diameter (D50) and volume mean diameter of the sweet potato starch before treatment were 13.73 and $14.68 \mu \mathrm{m}$, respectively; while in comparison, they were 68.81 and $85.80 \mu \mathrm{m}$, separately, after treatment at different explosion pressures (2.4 MPa). This result was induced by the puffing effect arising as a result of the SE process.

\section{DISCUSSION}

The SE displays an effect of breaking macromolecular lattices at a molecular level and exerts various synergistic effects similar to acid hydrolysis, thermal degradation, mechanical fracture, oxygen bond failure, and structural rearrangement. The physical and chemical structures of the raw materials can be changed to a significant extent during processing.

In SE treatment process, a gelatinization effect occurred so as to break the granule structures when the sweet potato starch was combined with high-temperature steam in the cylinder. When the pneumatic valve was opened, after maintaining the applied pressure for a certain time, the pressure was reduced suddenly and the materials exploded, leading to rapid particle expansion. Some particles were broken up to form micro-molecular particles while some unruptured particles formed larger, irregular particles. The molecules of the starches were rearranged to form well-organized crystalline textures after sub-cooling. Furthermore, the texture was more compact in the form of recrystallized fragments with inhomogeneous shapes and sizes.

\section{CONCLUSION}

The molecular chains of sweet potato starch are fractured to decrease their degree of polymerization after SE treatment. As a result, the proportion of the starch with shorter molecular chains and the crystallization index of the starches, increase. Therefore, SE technology, when used as a pre-treatment method, can effectively increase the crystalline texture of sweet potato starch.

\section{DECLARATIONS}

\section{Acknowledgement}

This study was funded by Major Breeding Project of Henan Institute of Science and Technology 
(no. 2013ZD04).

\section{Conflict of Interest}

No conflict of interest associated with this work.

\section{Contribution of Authors}

The authors declare that this work was done by the authors named in this article and all liabilities pertaining to claims relating to the content of this article will be borne by them.

\section{Open Access}

This is an Open Access article that uses a funding model which does not charge readers or their institutions for access and distributed under the terms of the Creative Commons Attribution License (http://creativecommons.org/licenses/by/ 4.0) and the Budapest Open Access Initiative (http://www.budapestopenaccessinitiative.org/rea d), which permit unrestricted use, distribution, and reproduction in any medium, provided the original work is properly credited.

\section{REFERENCES}

1. Wenjie S, Hongzhang C. Study on loading coefficient in steam explosion process of corn stalk. Bioresour Technol 2015; 179: 534-542.

2. Konstantin GB, Anna A K, Maria A G, Janis G, Sergey S, Dmitry G, Ivan NZ. Application of steam explosion as a method of wood matrix thermochemical activation. $J$ Indian Acad Wood Sci 2016; 13(1): 82-89.
3. Zhengdao $Y$, Bailiang Z, Fuqiang $Y$, Guizhuan $X$, Andong S. A Real Explosion: The Requirement of Steam Explosion Pretreatment. Bioresour Technol 2012; 121: 335-341.

4. Marzieh S, Maryam MK, Hamid Z, Ilona SH, Keikhosro K. Techno-economical study of biogas production improved by steam explosion pretreatment. Bioresour Technol 2013; 148: 53-60.

5. Guangping $H$, James $D$, Shuyin Z, Bicho $P$, Qinglin $H$. Effect of Steam Explosion Treatment on Characteristics of Wheat Straw. Ind Crops Prod 2010; 31(1):28-33.

6. Yuzhen Z, Lan W, Hongzhang C. Formation Kinetics of Potential Fermentation Inhibitors in a Steam Explosion Process of Corn Straw. Appl Biochem Biotechnol 2013; 169(2): 359-367.

7. Pengilly C, García-Aparicio MP, Diedericks D, Görgens J. Optimization of Enzymatic Hydrolysis of Steam Pretreated Triticale Straw. BioEnergy Res 2016; 9(3): 851-863.

8. McIntosh S, Zhanying Z, Palmer J, Hengho W, Doherty $W$, Vancov, T. Pilot-scale cellulosic ethanol production using eucalyptus biomass pre-treated by dilute acid and steam explosion. Biofuels Bioprod Biorefin 2016; 10(4): 346-358.

9. Feng Z, Qunyu G, Zhong H, Xinan Z, Shujuan Y. Structural properties and digestibility of pulsed electric field treated waxy rice starch. Food Chem 2016; 194: 1313-1319.

10. Li GL, Liu BG, Zhang GC, Zeng J, Sun JL, Ma HJ. Characterization of Digestion Resistance Sweet Potato Starch Phosphodiester, Trop J Pharm Res 2014; 13 (9): 1393-1400.

11. Peng L, Fangyi L, Jianfeng L, Kaikai G, Gang L. Applications of Infrared Spectrometry in Molecular Groups Analysis of Plasticized Starch . Adv Mater Res 2013; 816: 1278-1281. 